\title{
NOTES
}

\section{Rapid Synthesis of Aromatic Polyamides by Microwave-Assisted Directed Polycondensation of Aromatic Diamines with Aromatic Dicarboxilic Acids}

\author{
Ki Hong Park, Shinji Watanabe, Masa-aki Kakimoto, \\ and Yoshio IMAI* \\ Department of Organic and Polymeric Materials, Tokyo Institute to Technology, \\ Meguro-ku, Tokyo 152, Japan \\ (Received August 26, 1992) \\ KEY WORDS Synthetic Method / Microwave-Assisted Polycondensation / \\ Rapid Polycondensation / Aromatic Polyamides /
}

Microwave has been recently used for the processing of polymers to accelerate curing or reactions, the high heating efficiency giving rise to remarkable rate enhancements and dramatic reduction of reaction times. ${ }^{1}$ Recent efforts include polymerization of acrylic monomers, ${ }^{2,3}$ crosslinking of various polymers such as epoxy resins, ${ }^{4-8}$ polyurethanes, ${ }^{9,10}$ and functionalized aromatic poly(ether ketone)s, ${ }^{11}$ and imidization of polyamic acid. ${ }^{12}$

Microwave irradiation using commercial domestic microwave ovens has also received increasing interest in organic synthesis due to significant effects over conventional reactions. ${ }^{13-19}$ Nevertheless, there have not yet been any reports concernig the utilization of these microwave-assisted organic reactions in the synthesis of condensation polymers. In this communication, we report the first successful application of microwave irradiation to the rapid synthesis of aromatic polyamides, which was carried out in a domestic microwave oven through the direct polycondensation of aromatic diamines with aromatic dicarboxylic acids in $N$-methyl-2-pyrrolidone (NMP) by using a combination of triphenyl phosphite and pyridine as a condensing agent. ${ }^{20}$

\section{EXPERIMENTAL}

\section{Apparatus}

The microwave oven used in these experiments was a domestic Mitsubishi RR-32 $(500 \mathrm{~W}, 2.45 \mathrm{GHz})$ with an on-off temperature controller. The sample temperature was determined by using a Teflon insulated thermocouple and recorded on a recorder. Figure 1 shows a schematic drawing of the microwave oven.

\section{Materials}

Aromatic diamines such as $m$-phenylenediamine (1a), p-phenylenediamine (1b), bis(4aminophenyl)methane (1c), and bis(4-aminophenyl) ether (1d), and dicarboxyic acids, isophthalic acid (2a) and terephthalic acid (2b), were purified in a usual way. NMP and pyridine were dried over calcium hydride and distilled. Triphenyl phosphite (TPP) and lithium chloride were used as received.

\section{Polymerization}

A typical preparation of aromatic polyamide under microwave irradiation was as follows: $0.500 \mathrm{~g}(2.5 \mathrm{mmol})$ of $1 \mathrm{~d}$ and $0.415 \mathrm{~g}(2.5 \mathrm{mmol})$ of $2 \mathbf{a}$ were placed in a $300 \mathrm{ml}$ round-bottomed 

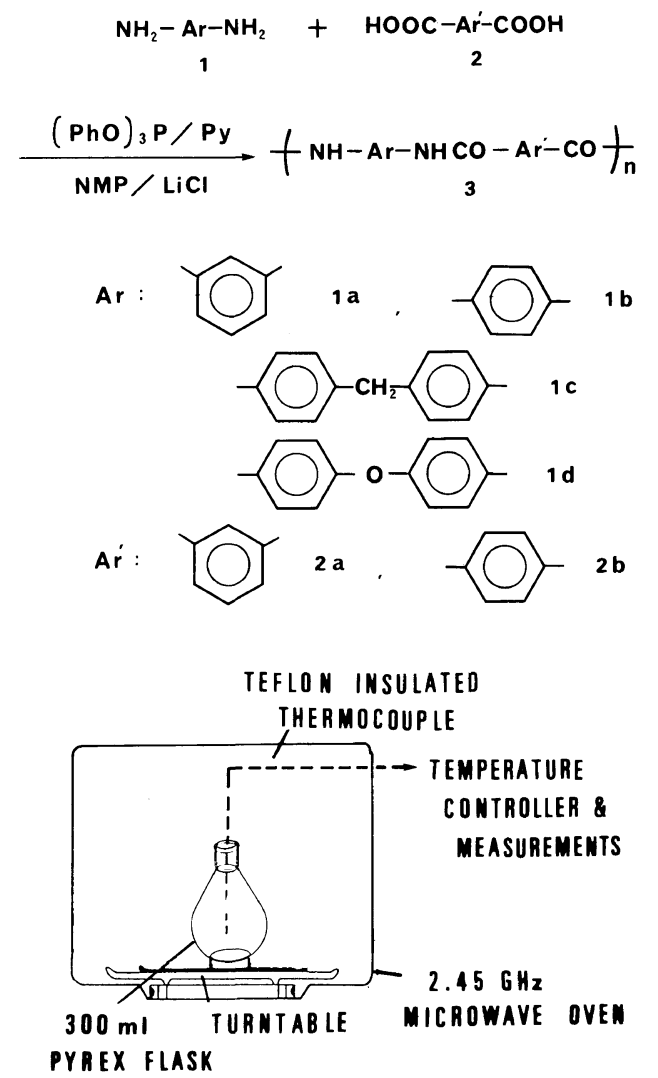

Figure 1. The apparatus for microwave-assisted polycondensation.

Pyrex flask and then added $5 \mathrm{ml}$ of NMP, $1.4 \mathrm{ml}$ of TPP, and $0.25 \mathrm{~g}$ of lithium chloride. The homogeneous mixture obtained was placed on the turntable in the domestic microwave oven (Figure 1), and the microwave was irradiated for $50 \mathrm{~s}$ in an air atmosphere. Immediately after that, the polymer formed was isolated by pouring the polymerization solution into $200 \mathrm{ml}$ of methanol, and was purified by refluxing with methanol for $3 \mathrm{~h}$. The polymer was dried under vacuum at $100^{\circ} \mathrm{C}$ for $24 \mathrm{~h}$. The yield of the polyamide was $0.78 \mathrm{~g}(94 \%)$ and the inherent viscosity was $0.86 \mathrm{dl} \mathrm{g}^{-1}$, measured at a concentration of $0.5 \mathrm{gd} \mathrm{l}^{-1}$ in concentrated sulfuric acid at $30^{\circ} \mathrm{C}$. The IR spectrum $(\mathrm{KBr})$ exhibited characteristic amide absorption bands at $3304 \mathrm{~cm}^{-1}(\mathrm{~N}-\mathrm{H})$ and $1653 \mathrm{~cm}^{-1}$ $(\mathrm{C}=\mathrm{O})$.
The polyamide by a conventional thermal method was prepared from $1 \mathbf{d}$ and $2 \mathbf{a}$ at $220^{\circ} \mathrm{C}$ for $1 \mathrm{~min}$ under nitrogen. The yield was $0.75 \mathrm{~g}$ $(90 \%)$ and the inherent viscosity was 0.98 $\mathrm{dlg}^{-1}$. The IR spectrum $(\mathrm{KBr})$ showed two amide absorptions at $3304 \mathrm{~cm}^{-1}(\mathrm{~N}-\mathrm{H})$ and $1653 \mathrm{~cm}^{-1}(\mathrm{C}=\mathrm{O})$.

\section{Measurements}

Infrared spectra were recorded on a Shimadzu FTIR-8100 spectrophotometer. Numberaverage molecular weight $\left(\bar{M}_{\mathrm{n}}\right)$ and weightaverage molecular weight $\left(\bar{M}_{w}\right)$ were determined by means of gel permeation chromatography (GPC) on the basis of a polyoxyethylene calibration on a JASCO BIP-I apparatus (Shodex GPC AD-80M/S polystyrene gel column) using $N, N$-dimethylformamide as an eluent.

\section{RESULTS AND DISCUSSION}

In the initial experiments, the polycondensation of $\mathbf{1 d}$ and 2a was carried out under microwave irradiation in NMP in the presence of TPP, pyridine, and lithium chloride, leading to the formation of polyamide 3da. Under the polymerization conditions employed, the temperature of the reaction mixture became elevated rapidly during the period of irradiation, reaching to $200^{\circ} \mathrm{C}$ (the boiling point of NMP) in a very short time of $30 \mathrm{~s}$, and then the mixture was superheated (curve A in Figure 2). This rapid temperature rise is ascribed to high dielectric constants of the mixture capable of efficient absorbing of microwave energy. Surprisingly, the polycondensation proceeded very rapidly along with rapid temperature rise, giving the polyamide having inherent viscosity of $0.86 \mathrm{dl} \mathrm{g}^{-1}$ after the reaction of only $50 \mathrm{~s}$ (curve B in Figure 2). Longer reaction time was abandoned because of both existence of the dangerous solvent vapors in the microwave oven which could cause a fire or explosion and possible degradation of the resulting polymer at such a high temperature. In fact, the 


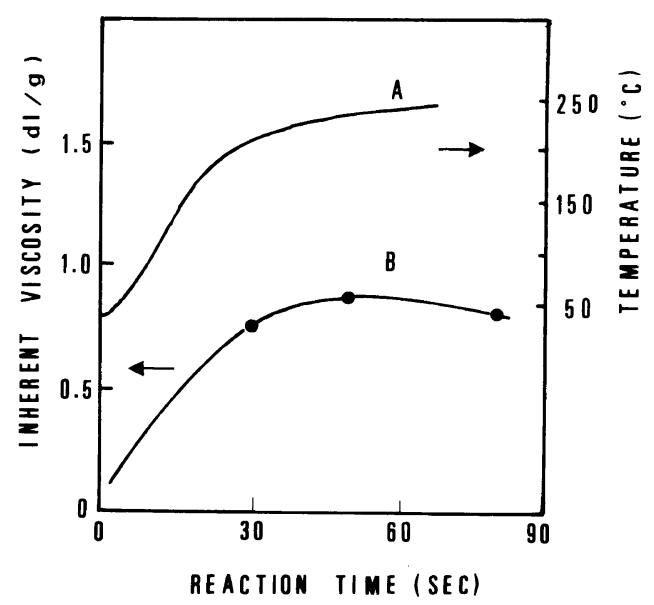

Figure 2. (A) temperature-time propile and (B) time dependence of inherent viscosity of polyamide 3da in the microwave-assisted polycondensation. Polymerization was carried out with $2.5 \mathrm{mmol}$ of each monomer (1d, 2a) in $5 \mathrm{ml}$ of NMP and $1.25 \mathrm{ml}$ of pyridine in the presence of $1.4 \mathrm{ml}$ of TPP and $0.25 \mathrm{~g}$ of $\mathrm{LiCl}$.

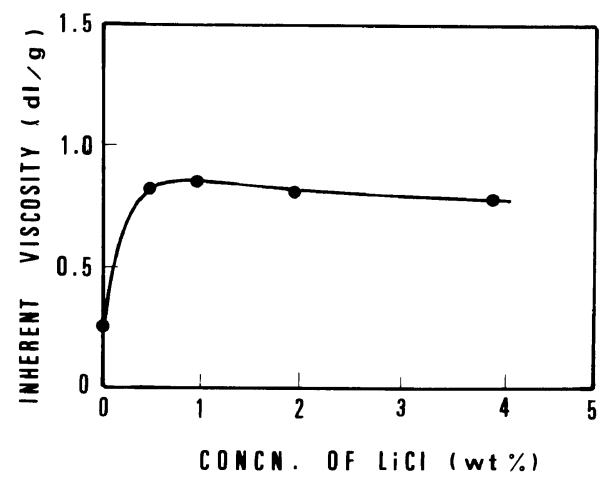

Figure 3. The effect of concentration of lithium chloride in the microwave-assisted polycondensation for polyamide 3da. Polymerization was carried out with $2.5 \mathrm{mmol}$ of each monomer (1d, 2a) in $5 \mathrm{ml}$ of NMP, $1.25 \mathrm{ml}$ of pyridine, and $1.4 \mathrm{ml}$ of TPP for $50 \mathrm{~s}$.

polyamide obtained after the reaction of $90 \mathrm{~s}$ discolored slightly. Therefore, the polymerization time was fixed to $50 \mathrm{~s}$ for further polymerizations.

To determine the optimum conditions for obtaining higher molecular weight polyamide 3da from 1d and 2a, the effects of concentration of lithium chloride and solvent ratio (NMP/ pyridine) were investigated. Figure 3 exhibits
Table I. Synthesis of polyamide $3 \mathrm{da}$ by the polycondensation in various solvent ratio under microwave irradiation ${ }^{\mathrm{a}}$

\begin{tabular}{|c|c|c|}
\hline \multirow{3}{*}{$\frac{\mathrm{NMP} / \mathrm{Py}}{\mathrm{ml} / \mathrm{ml}}$} & \multicolumn{2}{|c|}{ Polymer } \\
\hline & \multirow{2}{*}{$\frac{\text { Yield }}{\%}$} & \multirow{2}{*}{$\frac{\eta_{\text {inh }}{ }^{\mathrm{b}}}{\mathrm{dl} \mathrm{g}^{-1}}$} \\
\hline & & \\
\hline $4 / 1$ & 94 & 0.86 \\
\hline $3 / 2$ & 95 & 0.86 \\
\hline $2 / 3$ & 96 & 0.85 \\
\hline $0 / 5$ & 85 & 0.28 \\
\hline
\end{tabular}

a Polymerization was carried out with $2.5 \mathrm{mmol}$ of each monomer (1d, 2a) in the presence of $1.4 \mathrm{ml}$ of TPP and $0.25 \mathrm{~g}$ of $\mathrm{LiCl}$ for $50 \mathrm{~s}$.

b Inherent viscosity was measured at a concentration of $0.5 \mathrm{gdl}^{-1}$ in concentrated sulfuric acid at $30^{\circ} \mathrm{C}$.

the effect of concentration of lithium chloride on inherent viscosity of the polymer formed by the microwave polycondensation for $50 \mathrm{~s}$. Lithium chloride usually enhances solubility of aromatic polyamides in amide-type solvents, and $4 \mathrm{wt} \%$ of lithium chloride were used for the synthesis of aromatic polyamides by a conventional thermal polycondensation. ${ }^{20}$ In the present case, however, only $1 \mathrm{wt} \%$ of lithium chloride was sufficient to obtain the polymer having the highest inherent viscosity.

Table I shows the effect of solvent ratio (NMP/pyridine) on the microwave-assisted polycondensation. All the mixed solvent systems afforded the polymer having the same inherent viscosity, regardless of the solvent ratio, while pyridine alone gave apparently inferior result owing to the lower solvency for polyamide.

The studies were then extended to the polycondensation of other monomer pairs to examine general applicability of the microwave-assisted polycondensation. Table II summarizes the results of the synthesis of various polyamides by the microwave method, those by a conventional heating method being included for comparison. The microwaveassisted polycondensation for 30 or $50 \mathrm{~s}$ 
Table II. Polycondensation of various monomers by microwave and conventional heating methods ${ }^{\mathbf{a}}$

\begin{tabular}{|c|c|c|c|c|c|c|c|c|}
\hline \multirow{2}{*}{\multicolumn{2}{|c|}{ Monomer }} & \multirow{4}{*}{ Polymer } & \multicolumn{3}{|c|}{ Microwave $^{b}$} & \multicolumn{3}{|c|}{ Conventional heating ${ }^{\mathrm{c}}$} \\
\hline & & & \multirow{2}{*}{$\begin{array}{c}\text { Reaction } \\
\text { Time }\end{array}$} & \multicolumn{2}{|c|}{ Polymer } & \multirow{2}{*}{$\begin{array}{l}\text { Reaction } \\
\text { Time }\end{array}$} & \multicolumn{2}{|c|}{ Polymer } \\
\hline \multirow[t]{2}{*}{ Diamine } & Diacid & & & Yield & $\eta_{\mathrm{inh}}^{\mathrm{d}}$ & & Yield & $\eta_{\mathrm{inh}}{ }^{\mathrm{d}}$ \\
\hline & & & $\mathrm{s}$ & $\%$ & $\mathrm{dl} \mathrm{g}^{-1}$ & s & $\%$ & $\mathrm{dl} \mathrm{g}^{-1}$ \\
\hline $1 \mathbf{a}$ & $2 a$ & 3aa & 50 & 87 & 0.43 & 60 & 86 & 0.27 \\
\hline $1 \mathrm{~b}$ & $2 \mathbf{a}$ & $3 \mathbf{b a}$ & 50 & 91 & $0.92^{\mathrm{e}}$ & 60 & 91 & 0.90 \\
\hline 1c & $2 \mathbf{a}$ & $3 \mathrm{ca}$ & 50 & 87 & 0.71 & 60 & 90 & 0.68 \\
\hline 1d & $2 a$ & 3da & 50 & 94 & 0.86 & 60 & 90 & 0.98 \\
\hline $1 \mathrm{a}$ & $2 b$ & $3 \mathbf{a b}$ & 30 & 91 & $0.21^{\mathrm{e}}$ & 40 & 86 & 0.20 \\
\hline $1 b$ & $2 b$ & 3bb & 30 & 86 & $0.28^{\mathrm{e}}$ & 40 & 85 & 0.23 \\
\hline $1 \mathrm{c}$ & $2 b$ & $3 \mathrm{cb}$ & 30 & 80 & $0.62^{\mathrm{e}}$ & 40 & 87 & 0.50 \\
\hline 1d & 2b & $3 d b$ & 30 & 90 & $0.67^{\mathrm{e}}$ & 40 & 92 & 0.54 \\
\hline
\end{tabular}

a Polymerization was carried out with $2.5 \mathrm{mmol}$ of each monomer in $5 \mathrm{ml}$ of NMP and $1.25 \mathrm{ml}$ of pyridine in the presence of $1.4 \mathrm{ml}$ of TPP and $0.25 \mathrm{~g}$ of $\mathrm{LiCl}$.

b Polymerization conditions were $30-230^{\circ} \mathrm{C}$ in air without stirring.

c Polymerization conditions were $220^{\circ} \mathrm{C}$ in nitrogen atmosphere with stirring.

${ }^{d}$ Inherent viscosity was measured at a concentration of $0.5 \mathrm{gd} \mathrm{l}^{-1}$ in concentrated sulfuric acid at $30^{\circ} \mathrm{C}$.

e Precipitation occurred during the polycondensation.

afforded a variety of polyamides having inherent viscosities in the range of $0.21-0.92$ $\mathrm{dlg}^{-1}$. These viscosity values were almost the same as those by the stirred thermal polycondensation at $220^{\circ} \mathrm{C}$ for $60 \mathrm{~s}(0.20-0.98$ $\left.\mathrm{dlg}^{-1}\right)$. It is notable that the microwave polycondensation using terephthalic acid (2b) as a diacid component for only $30 \mathrm{~s}$ gave somewhat better results with respect to inherent viscosity of the polyamides over a conventional heating method, despite that the microwave polycondensation proceeded along with precipitation of the resulting polymers.

The polymers obtained by the microwave method were confirmed to be the corresponding polyamides by means of IR spectroscopy, which were identical with those by a conventional heating method. The $\bar{M}_{w} / \bar{M}_{n}$ values corresponding to molecular weight distribution for the polyamides by the microwave method, determined by means of GPC, were in the range of $1.7-2.2$, while those for the polyamides by a conventional method were $1.5-2.2$. Therefore, no marked differ- ences in $\bar{M}_{w} / \bar{M}_{n}$ values were observed in the polyamides obtained by the two different methods. This strongly suggests that the polymerization system under microwave irradiation was thermally uniform even though the polymerization was carried out without stirring.

\section{CONCLUSION}

We have developed a novel method for the rapid synthesis of aromatic polyamides by the direct polycondensation of aromatic diamines with aromatic dicarboxilic acids under microwave irradiation. A series of polyamides with moderate inherent viscosities of $0.21-0.92$ $\mathrm{dl} \mathrm{g}^{-1}$ could be obtained in excellent yields by the microwave-assisted polymerization for only $30-50 \mathrm{~s}$. The microwave heating effect was somewhat observed in these experiments. Therefore, the present method seems to have considerable potential for the rapid synthesis of other types of condensation polymers. 


\section{REFERENCES}

1. J. Mijovic and J. Wijaya, Polym. Composites, 11, 184 (1990).

2. M. Teffal and A. Gourdenne, Eur. Polym. J., 19, 543 (1983).

3. D. A. Doori, R. Huggett, J. F. Bates, and S. C. Brooks, Dental Materials, 4, 25 (1988).

4. F. M. Thuillier, Polymer, 27, 206 (1986).

5. Q. L. Van and A. Gourdenne, Eur. Polym. J., 23, 777 (1987)

6. N. Beldjoudi, Eur. Polym. J., 24, 49 (1988).

7. N. Beldjoudi, Eur. Polym. J., 24, 53 (1988).

8. N. Beldjoudi, Eur. Polym. J., 24, 265 (1988).

9. H. Jullien, Polymer, 26, 506 (1985).

10. B. Silinsky, C. Kuzmycz, and A. Gourdenne, Eur. Polym. J., 23, 273 (1987).

11. J. C. Hedrick, D. A. Lewis, G. D. Lyle, S. D. Wu, T. C. Ward, and J. E. McGrath, Proceedings of ACS Division of Polymeric Materials Science and Engineering, Vol. 60, 1989, p 438
12. D. A. Lewis, J. D. Summers, T. C. Ward, and J. E. McGrath, J. Polym. Sci., A, Polym. Chem., 30, 1647 (1992).

13. R. Gedye, F. Smith, K. Westaway, H. Ali, L. Baldisera, L. Laberge, and J. Rousell, Tetrahedron Lett., 27, 279 (1986).

14. R. J. Giguere, T. L. Bray, S. M. Duncan, and G. Majetich, Tetrahedron Lett., 27, 4945 (1986).

15. R. J. Giguere, A. M. Namen, B. O. Lopez, A. Arepally, and D. E. Ramos, Tetrahedron Lett., 28, 6553 (1987)

16. R. N. Gedye, F. E. Smith, and K. C. Westaway, Can. J. Chem., 66, 17 (1988).

17. A. B. Alloum, B. Labiad, and D. Villemin, J. Chem. Soc., Chem. Commun., 389 (1989).

18. E. Gutierrez, A. Loupy, G. Bram, and E. Ruiz-Hitzky, Tetrahedron Lett., 30, 945 (1989).

19. S.-T. Chen, S.-H. Chiou, and K.-T. Wang, J. Chem. Soc., Chem. Commun., 807 (1990).

20. N. Yamazaki, M. Matsumoto, and F. Higashi, $J$. Polym. Sci., Polym. Chem. Ed., 13, 1373 (1975). 